\title{
Trial for Using Emergency Vaccination for Controlling Duck Virus Hepatitis (DVH) Outbreaks in Ducks \\ Sabry, E.O. ${ }^{1}$, Hemat, S. Elsayed ${ }^{1}$, Naglaa Hagag ${ }^{2}$, Wesam Mady ${ }^{2}$ \\ ${ }^{1}$ Department of Poultry Diseases, Animal Health Research Institute, Benha Branch, Benha, Egypt \\ ${ }^{2}$ Reference Laboratory for Veterinary Quality Control on Poultry Production, Animal Health Research Institute, Ministry of Agriculture, Dokki, Giza, Egypt
}

\begin{abstract}
This study was conducted to evaluate the use of emergency vaccination to control DVH in ducks. Five liver samples were collected from Pekin ducks showing clinical symptoms of DVH from Kalubia province in summer 2016. The virus was isolated in specific pathogenic free (SPF) embryonated chicken eggs $\left(\mathrm{ECE}_{\mathrm{S}}\right)$. The clinical samples were examined by generic RT-PCR followed by partial sequencing of the $3 \mathrm{D}$ gene; the results revealed that the isolate was characterized as Duck hepatitis A virus resembling the recent Egyptian virus DHV/Duck/Egypt/AL-Gharbia/2014 belonging to serotype- 1 with highest percent identity of (97.9\%), and with Duck hepatitis-A virus vaccine with (79.4\%) identity . The results obtained from emergency vaccination experiment indicated that emergency vaccination against DVH in young duckling in the experimentally infected and emergently vaccinated group gave good protection against infection with no deaths after emergency vaccination till the end of the experiment (40 days). In contrast, the second group (experimentally infected and not emergently vaccinated) showed deaths reached up to $40 \%$ of the ducklings and the lesions in dead and survived ducklings were severe. Therefore, emergency vaccination can be used effectively to face DVH outbreaks as a tool to control the disease.
\end{abstract}

Key words: DVH, SPF, RT-PCR and emergency vaccination.

\section{Introduction}

Duck virus hepatitis is acute fatal disease of ducklings caused by 4 types of virus; (DHV) types DHV1, DHV-1a (a variant strain of DHV-1), DHV-2 and DHV-3, and it is on the list of diseases notified to the World Organization for Animal Health (OIE) (OIE, 2010). The most common and widespread is DHV-1, is a member of family picornaviridae in the new genus Avihepatovirus which causes a highly lethal, acute, contagious infection in ducklings under 6 weeks of age and, frequently, under 3 weeks of age and may cause up to $90 \%$ mortality in neonatal ducks 
(Gough and Spackman, 1981), It does not occur in older birds.

DVH type 1 is RNA virus of $20-40$ $\mathrm{nm}$ diameters and its genome consists of 7691 nucleotides (Ding and Zhang, 2007). Three genotypes and serotypes of DHV type I have been identified and designated duck hepatitis A virus (DHAV) types 1,2 and 3 (Wang et al. 2008).

DHV-1, is the most virulent and most common serotype that spread worldwide. Both DHV-2 and DHV3 were identified later as astrovirus, known as duck astrovirus type-1 (DAstV-1) and duck astrovirus type-2 (DAstV-2) respectively (Todd et al., 2009). DHAV is divided genetically into three different genotypes found in South Asia, the original genotype DHAV1 , a new genotype DHAV-2 isolated in Taiwan and a new genotype DHAV-3 isolated in South Korea and China $(\boldsymbol{F u}, \mathbf{Y}$. et al., 2008).

DHAV can be transmitted by parenteral or oral route, but egg transmission has not been occurred yet. The virus is rapidly propagated in chick and duck embryo (Woolcock, 2003).

The clinical disease is characterized by lethargy and ataxia followed by opisthotonos and death. Mortality occurs within 3-4 days, with most deaths on the second day. Gross pathological changes appear mainly in the liver, which is enlarged and displays distinct petechial and ecchymotic haemorrhages, as well as Spleen enlargement and swelling of the kidneys (OIE, 2010).

Control of DHV type I infections can be achieved by the use of live attenuated and inactivated virus vaccines. Breeder ducks are vaccinated to confer passive immunity to ducklings so that immunity is transferred via the yolk to newly hatched birds. Day-old ducklings are actively immunized by live attenuated virus vaccines and also can be passively protected with a chicken egg yolk antibody preparation. The emergency control measures can effectively stop the spread of infection (Liao et al., 1991)

\section{Material and Method}

1-Field samples collection and preparation:

Livers showing pathologic lesions were collected from one suspected duck virus hepatitis infected farm . The liver samples were homogenized and suspended in sterile Phosphate Buffer Saline (PBS) and the suspension was clarified by centrifugation at 3000 $\mathrm{rpm}$ at $4^{\circ} \mathrm{C}$ for 15 minutes. The supernatant fluid part stored at -20 $C$ until used.

\section{2- Duck virus hepatitis vaccine:}

Live attenuated duck virus hepatitis vaccines obtained from Veterinary serum and Vaccine Research Institute (VSVRI), Abbassia, Cairo, Egypt.

3-Virus isolation and propagation (According to OIE, 2010): 
$0.2 \mathrm{ml}$ of liver homogenate was inoculated into allantoic sac of 9 day old SPF embryonated chicken eggs (ECE), after 7 days the embryo was examined for gross pathological changes and the allantoic fluid was harvested and used for RNA extraction, RT-PCR and sequencing.

\section{4- RNA extraction and RT-PCR:}

The isolated virus was confirmed by reverse transcriptase polymerase chain reaction for duck virus hepatitis. RNA extraction was done by using QIAamp Viral RNA Mini Kit (Qiagen, Valencia, Calif., USA) according to the manufacturing instructions as procedures. RT-PCR was done by using PrimeScript ${ }^{\mathrm{TM}}$ One Step RT-PCR Kit (Takara Bio USA, Inc.) by using specific primers for 3D gene of duck virus hepatitis, Forward primer: DHV-1 ComF (5'-AAG-AAG-GAG-AAAATY-[C or T]- AAG-GAA-GG-3'), and reverse primer: DHV-1 ComR (5'-TTG-ATG-TCA-TAG CCCAAS- $[\mathrm{C}$ or G]-ACA-GC-3') Flanked by a 467 bp (OIE, 2010). The PCR product was separated by gel electrophoresis using $1.5 \%$ agarose gel stained with ethidium bromide and visualized under ultraviolet light using $\mathrm{Gel}$ documentation system.

5- Sequencing and phylogenetic analysis:

The isolated virus was sequenced partially for the 3D gene using specific primers using BigDye Terminator v3.1 Cycle Sequencing Kit with Genetic analyzer (ABI-
3130, Applied Biosystems, Foster City, CA), Amino acid sequences were deduced from the generated nucleotides using BioEdit software version 7.1.7 (Hall, 1999). Sequences of query and representative DHAVs were retrieved from the GenBank database, Phylogenetic analyses were done using MEGA6 (Tamura et al., 2013). Consensus unrooted tree were generated with 1000 bootstrap replicates.

\section{6- Emergency Vaccination experiment:}

Sixty one-day old Pekin ducklings were divided into 3 groups, each group contains 20 ducklings; Group 1: Not vaccinated and not infected (negative control). Group 2: Infected at 7 days old with $0.2 \mathrm{ml}$ of $10^{3.7}$ EID $_{50}$ of isolated virus and not vaccinated (positive control group). Group 3: infected at 7 days old with $0.2 \mathrm{ml}$ of $10^{5}$ EID $_{50}$ of isolated virus and emergency vaccinated (at the beginning of clinical signs) by intramuscular immunization with $0.2 \mathrm{ml}\left(10^{5}\right.$ EID $_{50}$ ) of live attenuated Duck virus hepatitis vaccine (VSVRI) per bird. The ducks were daily observed for clinical signs, pathological lesions and mortalities for a period of 40 days. All ducking was fed on commercial standard ration, the ration and fresh water was offered to the ducking at libitum.

\section{Results}

Inoculation of SPF chicken embryos: 
The inoculated SPF chicken embryos showed gross pathological lesions as stunting embryos, subcutaneous hemorrhage and edema of the abdominal region. The livers were swollen, yellow color and showed some necrotic foci.

RT-PCR sequencing and phylogenetic analysis:

$467 \mathrm{bp}$ fragment of the partial 3D gene was amplified by RT-PCR, The nucleotides sequences of partial 3D gene

DHV/Duck/Egypt/F139/2016 virus showed (97.9\%) identity percent with strains isolated from Gharbia like DHV/Duck/Egypt/AL-Gharbia/ 2014 and with Duck hepatitis -Avirus-Vaccine with $(79.4 \%)$, as shown in Fig. 2, The phylogenetic analysis reveals that the isolated Egyptian strain in this study were distant from the vaccinal strain used in Egypt and closely related to the Asian strains.

\section{Emergency}

vaccination

Experiment

The ducklings in the group which neither experimentally infected nor vaccinated not showed any symptoms or Lesions of DVH.

The ducklings in the group which experimentally infected and not emergently vaccinated (group 2) were showed the following symptoms (at the 2nd day of infection) fall over on their sides, struggle for a short period with spasmodic paddling movements of their legs, then die with the head were stretched upwards and backwards (Opisthotonous). The symptoms appear consequently in the ducklings of that group and the deaths reached $40 \%$ of the ducklings ( 8 from 20). The lesions of the experimentally affected duckling were enlarged fatty liver with a number of petechial and ecchymotic hemorrhages and enlarged kidneys. The Lesions in dead and survived ducklings were severe. (Fig. 3).

The ducklings in the group which experimentally infected and emergently vaccinated (group 3) were showed the symptoms of DVH at the $2^{\text {nd }}$ day of infection in one duckling. This group was vaccinated as an emergency vaccination by DVH vaccine (VSRI) by $1 / \mathrm{M}$ route at a dose of $0.2 \mathrm{ml}$ 105EID50. The results in that group after emergency vaccination shows that no symptoms appear on the other ducklings of that group till the end of the experiment -40 daysand no other deaths were occurred except the only one died firstly after the infection. The lesions of the DVH in survived ducklings were less prominent (Fig. 3). 


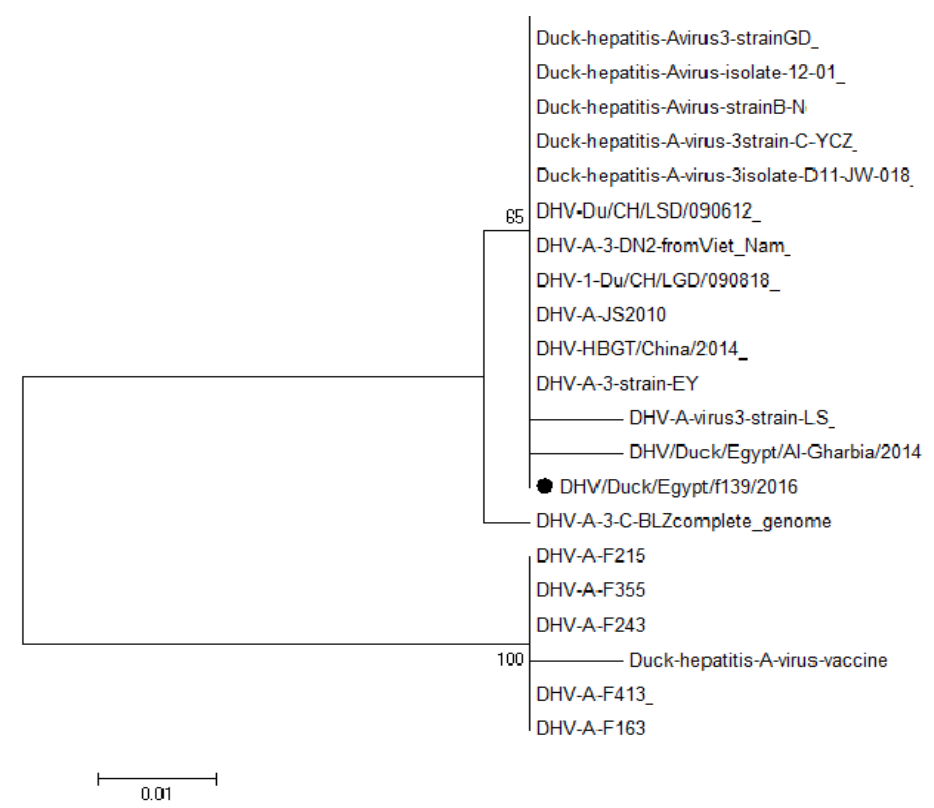

Fig1: Phylogenetic analysis of DHV/Duck/Egypt/F139/2016 based on partial 3D gene analysis

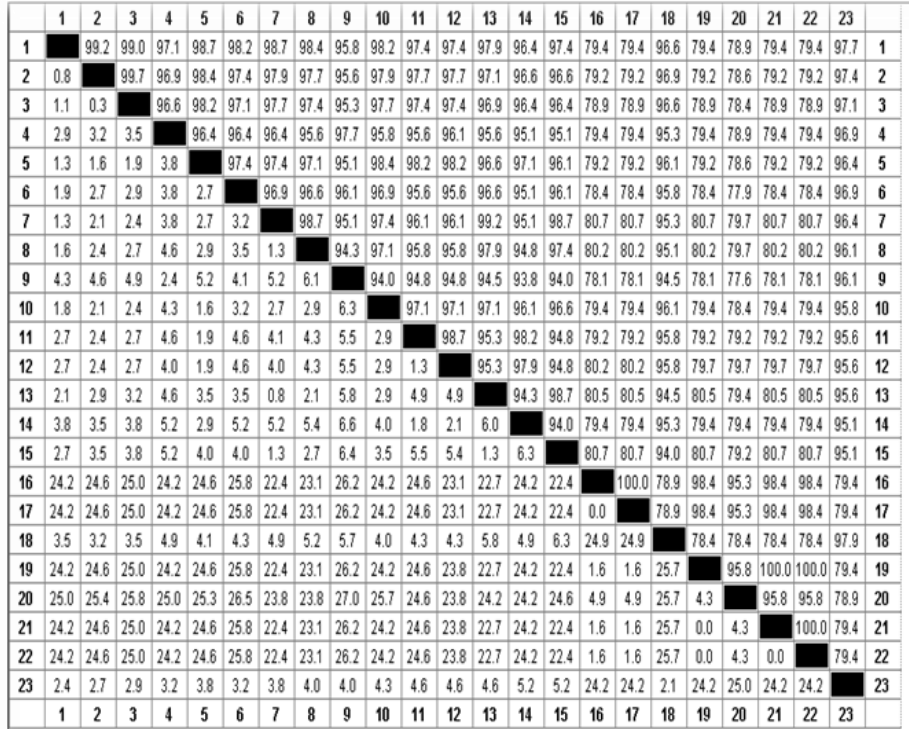

Fig.2: $3 D$ Nucleotide identities and divergence Egypt/F139/2016 compared to other selected strains.
Duck-hepatitis-Avirus3-strain $G D$, Duck-hepatitis-Avirus-isolate-12-01, Duck-hepatitis-Avirus-strainB-N,comp Duck-hepattis-A-virus-3strain-B63, Duck-hepattis-A-virus-3strain-C.YCZ Duck-hepattis-A-virus-3isolate-D11DHV-DUUCHLSDI090612, DHN-A-3-C.BLZ, complete DHN-A-3-DN2-fromViet DHN-1-DUUCHLGO1090818, DHN-A.JS2010, DHM-HBGTIChina2014 Duck-hepattis-virus-SD01, DHV-A-3-strain-EY, DHV-A-virus3-strain-LS, DHVA-F215 DHV-A.F355 DHVIDUCWEgyptal-Gharbia/2014 DHV-A.F243 Duck-hepattis-A-virus-vaccine DHV-A.F413 DHV-A.F163 DHVDUchEgyptr139/2016 

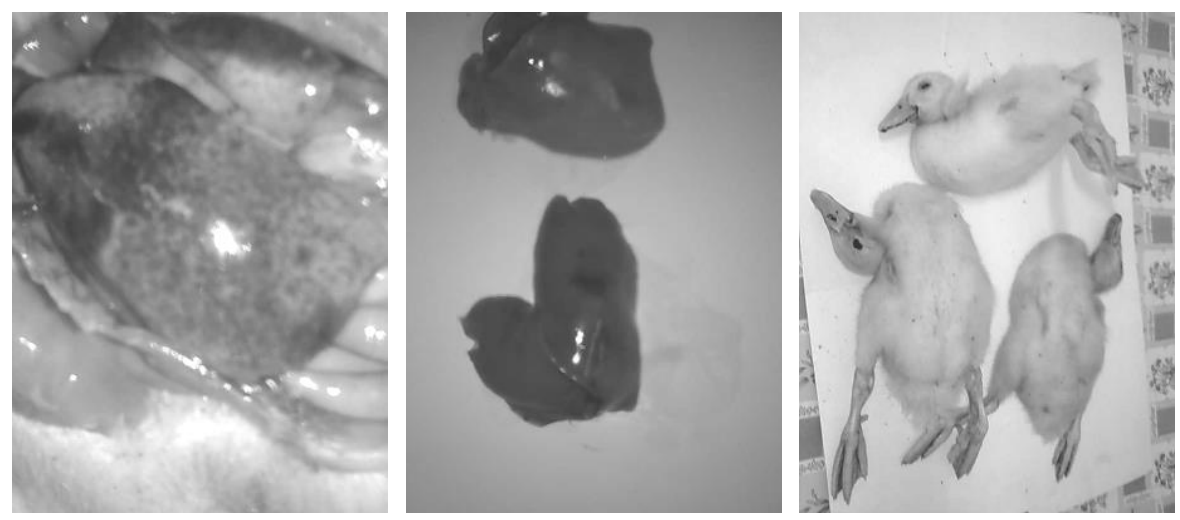

Fig. 3: Symptoms and lesions of infected ducklings with DVH isolate a. Infected non vaccinated. The lesion in dead ducklings were sever enlarged fatty liver with sever petechial and ecchymotic hemorrhage.

p. Infected and vaccinated. Less prominent lesions in surviving ducklings.

C. Opithotonous in infected ducklings

\section{Discussion}

Duck viral hepatitis (DHV) is an acute, contagious, highly fatal disease of young ducklings, which was first described on Long Island, NY, USA, in 1949 (Levine and Fabricant, 1950). Classification of DVH strains has been divided into three serotypes: DHV-1, DHV-2 and DHV-3. The virus DHV-2 and DHV-3 are members of Astrovirus (Tood, D. et al., 2009). Phylogenetic analysis of DHAV revealed that, the variant strains are found in South Asia (Kim, M.C., et al., 2007 and Gao, J. et al., 2012). Signs of DVH- I infection are per acute, death usually follows within an hour of their onset. Affected birds fall over on their sides and, after a short struggle, with paddling movements of the legs, the birds die. The head is usually stretched upwards and backwards (opisthotonos) (Gough and McNutly, 2008), this agree with our results as affected ducklings were showing nervous signs and opisthonous. On postmortem examination the main lesion was enlargement in the liver with a number of petechial and ecchymotic hemorrhages, same observation were also recorded by (Gough and McNutly 2008).

Diagnosis of DHAV type I virus infection is based on virus isolation following the inoculation of organ suspension from affected ducklings into the allantoic sac of 9-day-old ECE or 10 to 14 day EDE (Woolcock,2008 and Woolcock ,2010). Levine and Fabricant (1950) were the first to propagate the virus in the allantoic sac of 9day-old chicken embryos. 10 - 60\% of the embryos died by the 5th or 6th day and were stunted or 
edematous. In our study, virus isolation was attempted by inoculation of $1 / 10$ dilution of liver suspension filtered through a 450 $\mathrm{nm}$ filter into 9 day old ECE through the allantoic cavity according to the standard protocol of $\boldsymbol{O I E}$ (2010). Eggs were candled daily for up to 7 days. Inoculated embryos showed stunting and subcutaneous hemorrhages over the whole body with edema, particularly of the abdominal and hind limb regions. The embryo livers were swollen, red in color and show necrotic foci. This agreed with that reported by Haider and Calnek ( 1979).

Rapid and specific detection of the DHAV RNA using different RTPCR assays were described by several authors Kim et al. (2007), Fu et al. (2008), Liu et al. (2008), Cheng et al. (2009), OIE (2010) and Wei et al. (2012). RT-PCR provide a potentially powerful technique in microbiological diagnostics, rapid, specific and sensitive tool for detection of suspected cases of DHAV in addition to molecular epidemiological screening (Hanaa A. El Samadony et al., 2016). Like other DHAVs, the Egyptian strains contain the xxCSGxxTxxNS motif which is highly conserved region in the 3D of all picornaviruses (Wang et al., 2008). In current study sequence and phylogenetic analysis revealed that DHV/Duck/Egypt/F139/2016 isolate cluster in the DHAV - 1 with highest percent identity of 97.9 with DHV/Duck/Egypt/ALGharbia/ 2014. In contrast the Egyptian isolate

DHV/Duck/Egypt/F139/2016 is distinguishable from the vaccine strain where the lowest identity (79.4) was observed in 3D gene. These results were similar to that obtained by Bayoumie, et al. (2015) and Erfan, et al. (2015).

Hanson and Tripathy (1976) \& Tripathy and Hanson (1986) stated that, DHV can be controlled in ducklings by various methods: injection of immune serum or yolk; immunization of breeding stock to ensure high levels of passively transferred antibody in the hatched ducklings and direct active immunization of ducklings with live avirulent strains of DHV type 1 .

Our results indicated that emergency vaccination against DVH in young duckling gave protection against infection where there are no deaths after emergency vaccination till the end of the experiment (40 days) in contrast the other group (experimentally infected and not emergently vaccinated) the deaths reached $40 \%$ of the ducklings. There is evidence that vaccination would be of benefit even at the start of an outbreak. These data are consistent with observations of Liao et al. (1991) who reported that the emergency vaccination control measures against DHAV can effectively stop the spread of infection. Moreover, Hwang, J. (1992) stated that, there 
was evidence that vaccination would be benefit even at the start of an outbreak. Therefore, emergency vaccination can be used effectively in the face of duck hepatitis virus outbreaks as a way to control the disease.

\section{References:}

Bayoumie, H.A.A. and L.K. Abd El Samie, (2015): Molecular characterization of a duck virus hepatitis isolate isolated from Sharkia governorate. Assiut Vet. Med. J., 61 (147): 56-65.

Cheng, A.; Wang, M.; Xin, H.; Zhu, D.; Li, X.; Chen, H.; Jia, R. and Yang, M. (2009): Development and application of a reverse transcriptase polymerase chain reaction to detect Chinese isolates of duck hepatitis virus type 1. J. Microbiol Methods. 77: 1-5.

Ding C. and Zhang D. (2007): Molecular analysis of duck hepatitis virus type 1. Virology 2007, 361, 917.

Erfan, A.M., A.A. Selim, M.K. Moursi, S.A. Nasef and E.M. Abdel whab (2015): Epidemiology and molecular characterization of duck hepatitis A virus from different duck breeds in Egypt. Vet. Microbiol., 177(3-4): 347-352.

$F u, Y$.; Pan, M.; Wang, $X$.; $X u, Y$.; Yang, $H$. and Zhang, D. (2008): Molecular detection and typing of duck hepatitis A virus directlyfrom clinical specimens. Vet Microbiol. 131: 247-257.

Gao, J.; J.Chen; X. Si; Xie, Y.; Zhu, X. Zhang; S.Wang and S.
Jiang (2012): Genetic variation of the VP1 gene of the virulent duck hepatitis A virus type (DHA-1) isolates in Shandong province of China. Virol., Sin., 27: 248-253.

Gough R. E. and Spackman D. (1981): studies with inactivated duck virus hepatitis vaccines in breeder ducks avian pathology, 10: 471-479,

Gough, RE. and McNulty, MS. (2008): In Poult. Dis. PP. 350-357. Edited by Pattison, McMulin, Broadbury and Alexander. Saunders ElSevier.

Haider, S.A. and B.W. Calnek (1979): In vitro isolation, propagation and characterization of duck hepatitis virus typeII. Avian diseases, 23: 715-729.

Hanaa A. El-Samadony, Laila A. Tantawy and Hoda M. Mekky (2016): Isolation and molecular detection of duck virus hepatitis. Global Veterinaria. 16(4): 314-322.

Hanson,L.E. and Tripathy (1976): oral immunization of Duckling with attenuated duck hepatitis virus. Dev Biol Stand. 33:357-363.

Hwang, J. (1972): Active immunization against duck hepatitis virus. Am J Vet Res. 33:25392544.

Kim, M.C.; Kwon, Y.K.; Joh, S.J.; Kim, S.J.; Tolf, C.; Kim, J.H.; Sung, H.W.; Lindberg, A.M. and Kwon, J.H. (2007): Recent Korean isolates of duck hepatitis virus reveal the presence of a new genoand serotype when compared to duck hepatitis virus type 1 type 
strains. Arch. Virol. 152, 20592072.

Levine P.P. and Fabricant J. A. (1950): hitherto-undescribed virus disease of ducks in North America. Cornell Vet. 40:71-86.

Liao, Y.K., Y.S. Lu, D.F. Lin, Y.L. Lee, S.H. Lee and S.Y. Chiu (1991): the outbreak and control of duck viral disease in Taiwan, 198990. ASPAC Food \& Fertilizer Technology Center, 9 p.

Liu, G.; Wang, F.; Ni, Z.; Yun, T.; $Y u, B$.; Huang, J. and Chen, J. (2008): Genetic diversity of the VP1 gene of (DHV-I) isolates from southeast China is related to isolate attenuation. Virus Res. 137, 137141.

OIE Terrestrial Manual (2010): Duck viral hepatitis. Chapter 2.3.8.

Todd, D., V.J. Smyth, N.W. Ball, B.M. Donnelly,M. Wylie, N.J. Knowles and B.M. Adair (2009): Identification of chicken enterovirus-like viruses duck hepatitis virus type 2 and duck hepatitis virus type 3 as astroviruses. Avian Pathol., 38: 2130.

Tripathy, D.N. and Hanson, L.E. (1986): Impact of oral immunisation against duck viral hepatitis in passively immune ducklings. Prev. Vet. Med., 4, 355360
Wang L., Pan M., Fu Y. and Zhang D. (2008): Classification of duck hepatitis virus into three genotypes based on molecular evolutionary analysis. Virus Genes, 37, 52-59.

Wei, C.Y.; Su, S.; Huang, Z.; Zhu, W.J.; Chen, J.D.; Zhao, F.R.; Wang, Y.J.; Xie, J.X.; Wang, $H$. and Zhang, G. (2012): Complete genome sequence of a novel DHAV discovered in southern China. J. Virol. 86, 10247.

Woolcock, P. (2010): DVH. In: Manual of Diagnostic Tests and Vaccines for Terrestrial Animals. Office International des Epizooties, Paris, France.

Woolcock, P.R. (2008): Duck hepatitis. In: A Laboratory Manual for the Isolation, Identification and Characterization of Avian Pathogens, 5th ed. L. DufourZavala, D.E. Swayne, J.R. Glisson, J.E. Pearson, W.M. Reed, M.W. Jackwood, and P.R. Woolcock, eds. AAAP, Jacksonville, FL. 175-178.

Woolcock, P.R., (2003): Duck hepatitis. In: Saif Y.M., H.J. Barnes, J.R. Glisson, A.M. Fadly, L.R. Mcdougald and D.E. Swayne, eds. Diseases of Poultry. Eleventh ed. Iowa State Press, Ames, IA., pp: 343-354. 


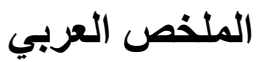

محاولة إستخدام التحصين الإضطرارى للسيطرة على إصابات فيروس إلتهاب الكبا

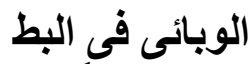

صبرى السيد عمر1، همت شفيق السيد عبد الرازقئ، نجلاء لمحم عبدالعزيز حسين حجاج²، وسام

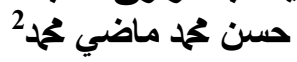

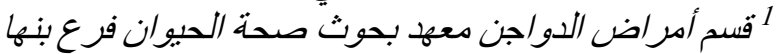

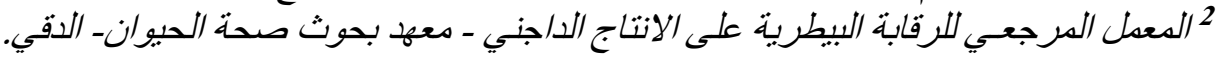

أجريت هذه الدراسة لتقييم استخدام التحصين الإضطر اري للسبطرة علي مرض إلتهاب الكبد الوبائي

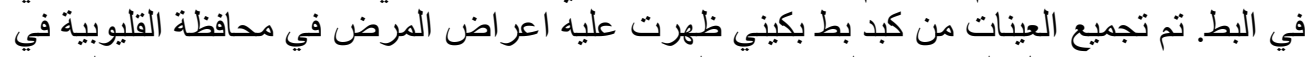

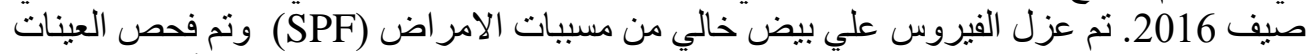

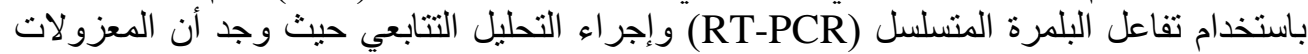

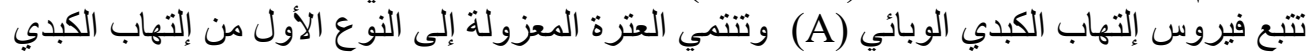

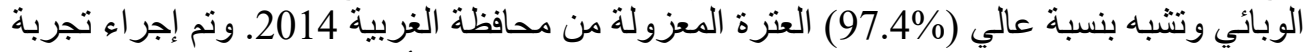

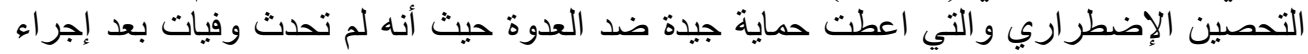

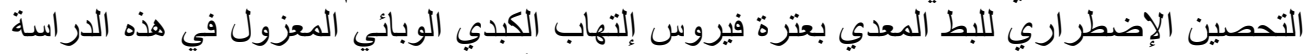

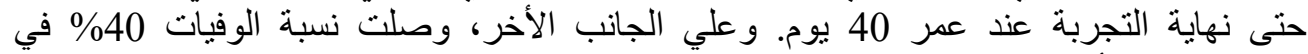

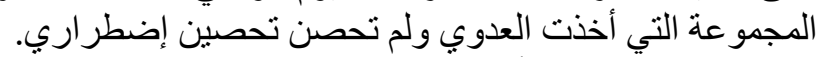

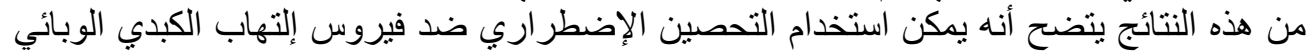

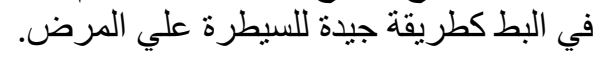

